\title{
Microincision vitrectomy surgery: experimental visualization and quantification of vitreous contamination
}

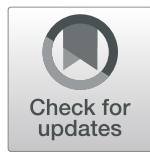

\author{
Yumiko Machida, Hiroyuki Nakashizuka* (D), Jun Shoji and Hiroyuki Shimada
}

\begin{abstract}
Background: To visualize and quantify vitreous contamination following microincision vitrectomy surgery (MIVS) using an experimental vitreous contamination model (EVCM).

Methods: Enucleated porcine eyes with fluoresbrite carboxylate microspheres applied to the conjunctival surface were used as a type 1 EVCM. Twenty-five- or 27-gauge (G) trocar cannulas were inserted through the conjunctiva and sclera, followed by the placing and opening of an infusion cannula. These procedures were monitored by an intraocular fiber catheter. Secondly, condensed microspheres were applied to an excised sheet of porcine sclera to serve as type 2 EVCM. Twenty-five- or 27-G trocar cannulas were inserted perpendicularly through the top of the sclera where the condensed microspheres were applied, an infusion cannula was inserted, $0.1 \mathrm{~mL}$ of saline solution injected through the infusion cannula, and samples collected. The fluorescence strength of samples was then measured using fluorophotometry.
\end{abstract}

Results: We visually detected fluorescent microspheres in 10/10 eyes with 25-G and 10/10 with 27-G MIVS. In the experimental quantification study, each MIVS gauge value was significantly higher than the control $(P<0.01)$. However, there was no significant difference between 25-G and 27-G MIVS.

Conclusions: MIVS carries the risk of introducing contamination directly into the eyes when the trocar cannula is inserted and infusion cannula is opened, even when a 27-G MIVS is used. Our study has shown it is essential that the surgeon be aware of the possibility of introducing contamination from the conjunctiva at all times during MIVS.

Keywords: Microincision vitrectomy surgery, Vitreous contamination, Vitrectomy, Postoperative endophthalmitis, Contamination, Fluoresbrite carboxylate microspheres, Fluorophotometry, Intraocular fiber catheter

\section{Background}

Recently, microincision vitrectomy surgery (MIVS) has become more common, making vitrectomy a safer procedure. However, serious complications, such as postoperative retinal detachment and postoperative endophthalmitis, are still sporadically observed. Postoperative endophthalmitis is the

\footnotetext{
*Correspondence: nkshizuk@gmail.com

Division of Ophthalmology, Department of Visual Sciences, Nihon University School of Medicine, Nihon University Hospital, 1-6 Kandasurugadai,

Chiyoda-ku, Tokyo 101-8309, Japan
}

most serious complication after vitrectomy, and likely to cause serious vision loss.

When 25-G MIVS was first developed and its use broadened, it was reported that endophthalmitis occurred more frequently with MIVS than with conventional 20-G vitrectomy. Endophthalmitis was reported to be 12 or 28 times more likely to develop after 25-G MIVS than 20-G MIVS [1, 2]. More recently, the incidence of post-MIVS endophthalmitis seems to have reduced due to preventative strategies, however, even in the latest review of endophthalmitis after 25-G MIVS,

(c) The Author(s). 2020 Open Access This article is licensed under a Creative Commons Attribution 4.0 International License, which permits use, sharing, adaptation, distribution and reproduction in any medium or format, as long as you give appropriate credit to the original author(s) and the source, provide a link to the Creative Commons licence, and indicate if changes were made. The images or other third party material in this article are included in the article's Creative Commons licence, unless indicated otherwise in a credit line to the material. If material is not included in the article's Creative Commons licence and your intended use is not permitted by statutory regulation or exceeds the permitted use, you will need to obtain permission directly from the copyright holder. To view a copy of this licence, visit http://creativecommons.org/licenses/by/4.0/ The Creative Commons Public Domain Dedication waiver (http://creativecommons.org/publicdomain/zero/1.0/) applies to the data made available in this article, unless otherwise stated in a credit line to the data. 
the occurrence rate of endophthalmitis has still been higher than that of 20-G vitrectomy. In 2010, Oshima et al. developed 27-G vitrectomy [3], and it has been gaining popularity, however, the postoperative endophthalmitis rate has not yet been reported.

Tominaga et al. [4] reported the bacterial detection rate from the vitreous immediately after sclerotomy was $22.5 \%$ in the $25-\mathrm{G}$ vitrectomy group with a two-step incision procedure, which was significantly higher than the 20-G group (2.4\%). This observation suggested conjunctiva-residing bacterium may be introduced into the eye in MIVS during the sclerotomy, but imaging data is lacking. We think it is important for the vitreous surgeon to have the clear images to understand how bacterial contamination can be introduced into the eye during MIVS.

In this study, we clearly visualized the mechanism of contamination and quantified the contamination of 25G and 27-G MIVS using our previously described experimental model [5].

\section{Methods}

Freshly harvested eyes from pigs butchered at age 6 months were used. We initially used enucleated porcine eyes as a Type 1 experimental vitreous contamination model (EVCM). The porcine eyes were fixed onto a Styrofoam head model with pins. A 23gauge (G) lighted ocular endoscope (AS-611; FiberTech Co., Ltd., Sakura-shi, Japan) was inserted through the pars plana at the 12-O'Clock position. After that, two or three drops of fluoresbrite carboxylate microspheres (2.5\% Solids-Latex, Polysciences, Inc., Warrington, PA) were applied to the conjunctival surface at the insertion site. The diameter of Carboxylate Microspheres $(1.0 \mu \mathrm{m})$ is similar to the size of Staphylococcus bacteria (Fig. 1ab). Twenty-five- or 27-gauge (G) trocar cannulas were inserted through the conjunctiva and sclera perpendicularly, followed by the insertion and opening of an infusion cannula. Procedures were monitored with an intraocular fiber catheter and repeated 10 times (Supplementary video).

For experimental quantification, a Type 2 experimental vitreous contamination model was developed: Condensed microspheres were prepared by centrifugation for $20 \mathrm{~min}$ at approximately $5000 \mathrm{rpm}$, and $7 \mu \mathrm{L}$ of the condensed microspheres were applied to an excised sheet of porcine sclera. Twenty-five- or 27-G trocar cannulas were then inserted perpendicularly through the top of the sclera where the condensed microspheres were applied. An infusion cannula filled with saline

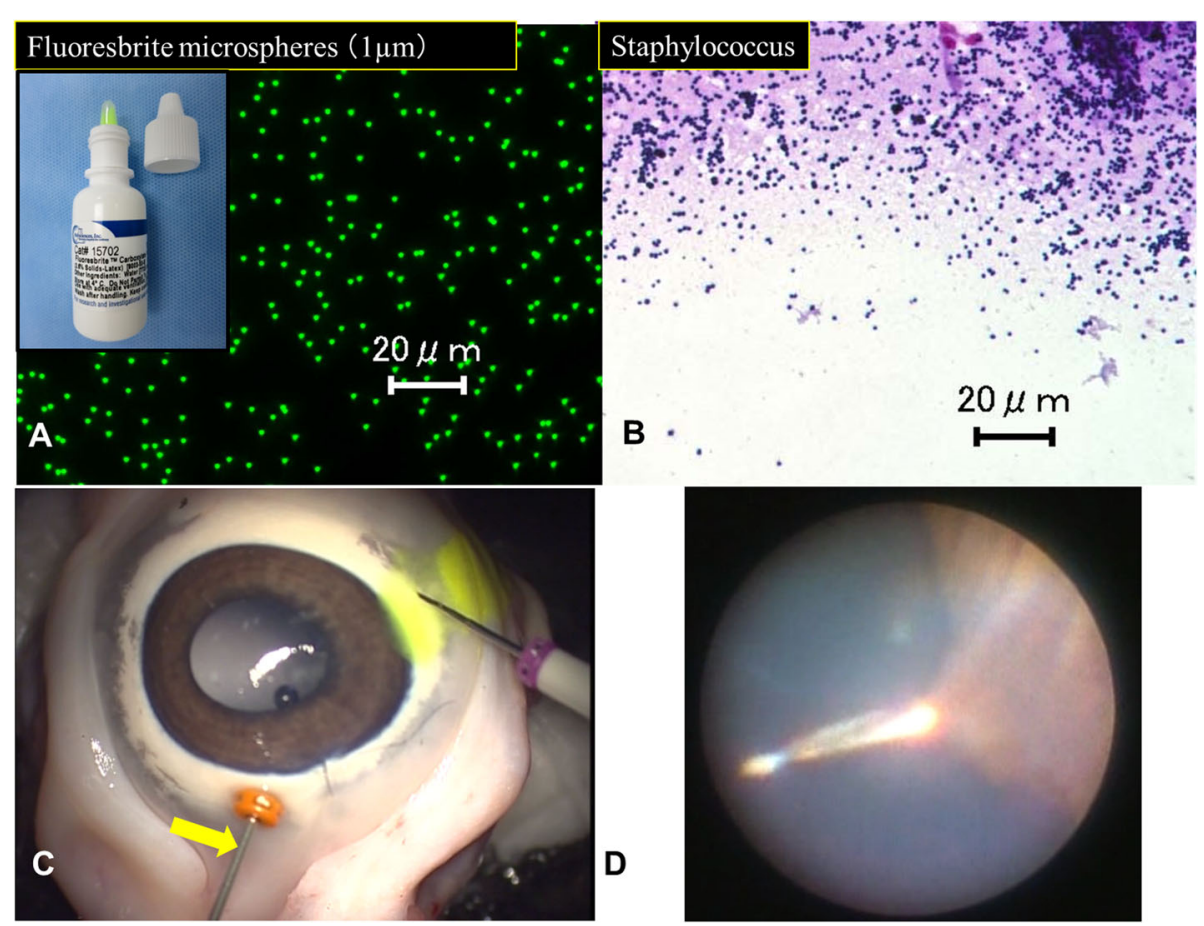

Fig. 1 Enucleated porcine eyes served as a type 1 EVCM. a, b Fluoresbrite Carboxylate Microspheres $(1.0 \mu \mathrm{m})$ are almost the same size as Staphylococcus bacteria. c, d Fluoresbrite carboxylate microspheres (2.5\% Solids-Latex; Polysciences, Inc.) were applied to the conjunctival surface at the insertion site. Twenty-five- or 27-gauge (G) trocar cannulas (27-G in this image) were inserted through the conjunctiva and sclera, followed by the placing and opening of the infusion cannula. These procedures were carefully monitored with an intraocular fiber catheter (yellow arrow). Scale bars, $20 \mu \mathrm{m}$ 
solution was then connected, and $0.1 \mathrm{~mL}$ of saline solution injected through the infusion cannula, and samples collected. As a control, $0.1 \mathrm{~mL}$ of saline solution was injected through sclera with a 27-G cannula without applying the microspheres. These procedures were repeated 10 times each for samples and controls. The fluorescence strength of the samples and controls were measured using fluorophotometry (Multi Label Counter ARVOmx 1420; PerkinElmer, Inc., Waltham, MA; Fig. 2b), with each specimen measured twice. Excitation and emission wavelengths were $485 \mathrm{~nm}$ and $535 \mathrm{~nm}$, respectively. The average value for each sample were used for statistical analyses. The Steel-Dwass test for multiple comparisons was used for statistical analyses of three samples (25-G sample, 27-G sample and 27-G control). Statistical analyses were performed using MAC Toukeikaiseki Ver. 2 (ESUMI Co Ltd., Tokyo, Japan).

\section{Results}

We visually detected fluorescent microspheres in all eyes injected through the $25-\mathrm{G}$ and $27-\mathrm{G}$ cannulas $(10 / 10$ for both the 25-G and 27-G; Fig. 3). When the cannula was opened, the microspheres spread into the vitreous and remained around the infusion site. In the experimental quantification study, the average fluorescence strength across samples and control were: $5.51 \pm 4.87 \times 10^{3}$ for $25-\mathrm{G} ; 12.60 \pm 14.98 \times 10^{3}$ for $27-\mathrm{G}$; and $2.45 \pm 0.39 \times 10^{3}$ for control (mean \pm standard deviation), (Supplementary file 1). The samples collected with each trocar gauge were significantly different from the control $(P<0.01$, 25-G; $P<0.01,27-\mathrm{G})$. However, there was no significant difference between 25-G and 27-G in regard to fluorescence strength (Fig. 4), (Supplementary file 2).

\section{Discussion}

Positive bacterial culture from the conjunctiva have been detected in $13-28 \%$ of cataract surgery, even after disinfection with povidone-iodine [6], suggesting it is difficult to completely eliminate bacteria on the conjunctiva. Postoperative endophthalmitis after MIVS has two opportunities to develop; during and after the operation. Tominaga et al. found significantly higher bacterial cultures in vitreous collected soon after trocar insertion with a 25-G compared with a 20-G [4], suggesting conjunctival bacteria are introduced during trocar insertion. It is thought that indigenous bacteria on the conjunctiva penetrate into the eye causing the endophthalmitis, as the pathogenic bacteria of endophthalmitis has been reported to be identical to normal conjunctival bacteria flora [7].

In the present study, microsphere penetration into the eye was visually confirmed in all cases using a $25-\mathrm{G}$ and 27-G cannula. With opening of the irrigation canula, spreading of microspheres around the cannula was especially evident. Furthermore, when microspheres were applied on the conjunctiva in a quantitative study, significantly higher fluorescence intensities were obtained from samples compared to controls. These indicate that contamination on the conjunctiva adheres to the trocar and cannula with trocar insertion, and that the open irrigation cannula enables dispersal into the eye.
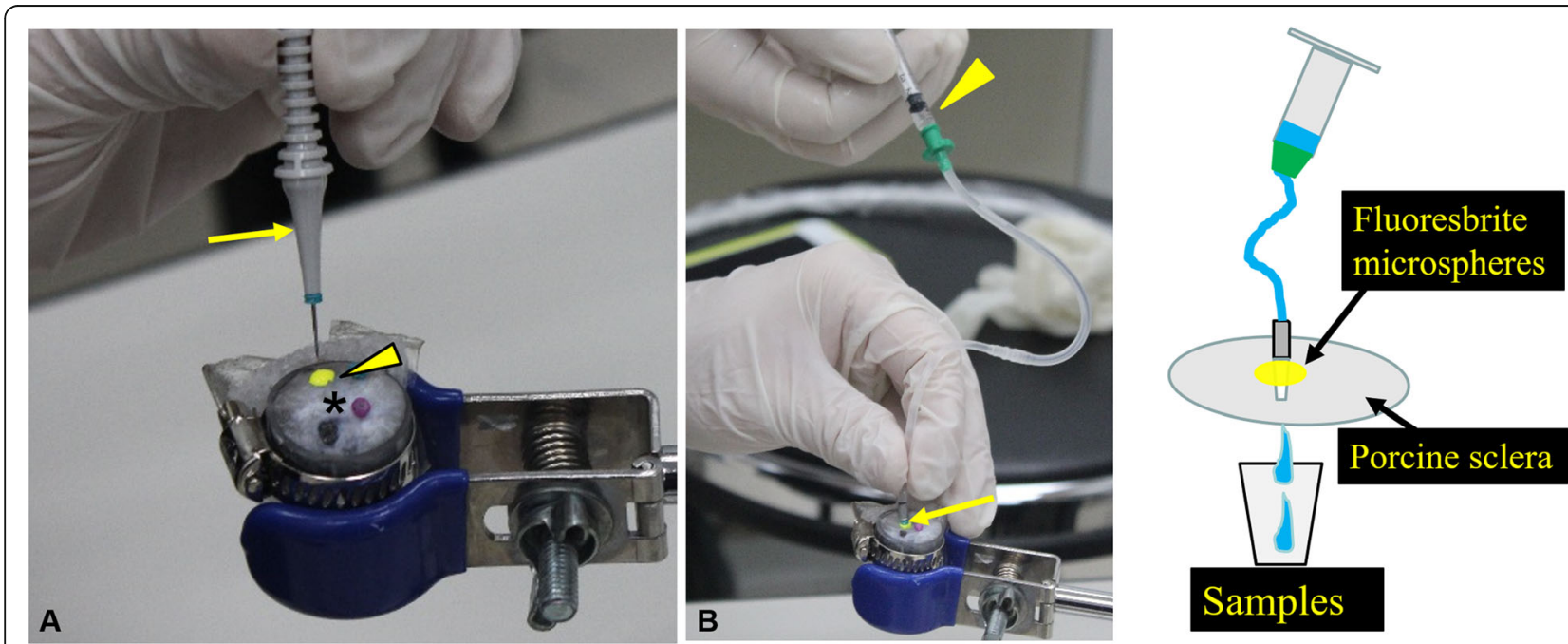

Fig. 2 An excised sheet of porcine sclera as a type 2 EVCM. a For experimental quantification, $7 \mu$ l of condensed microspheres (arrowhead) were applied to an excised sheet of porcine sclera (asterisk). Twenty-five- or 27-G trocar cannulas (arrow) were inserted from the top of an applied condensed microsphere through the sclera. b An infusion cannula was filled with saline solution (arrow), then $0.1 \mathrm{~mL}$ of saline solution (arrowhead) was injected through infusion cannula, and samples collected 


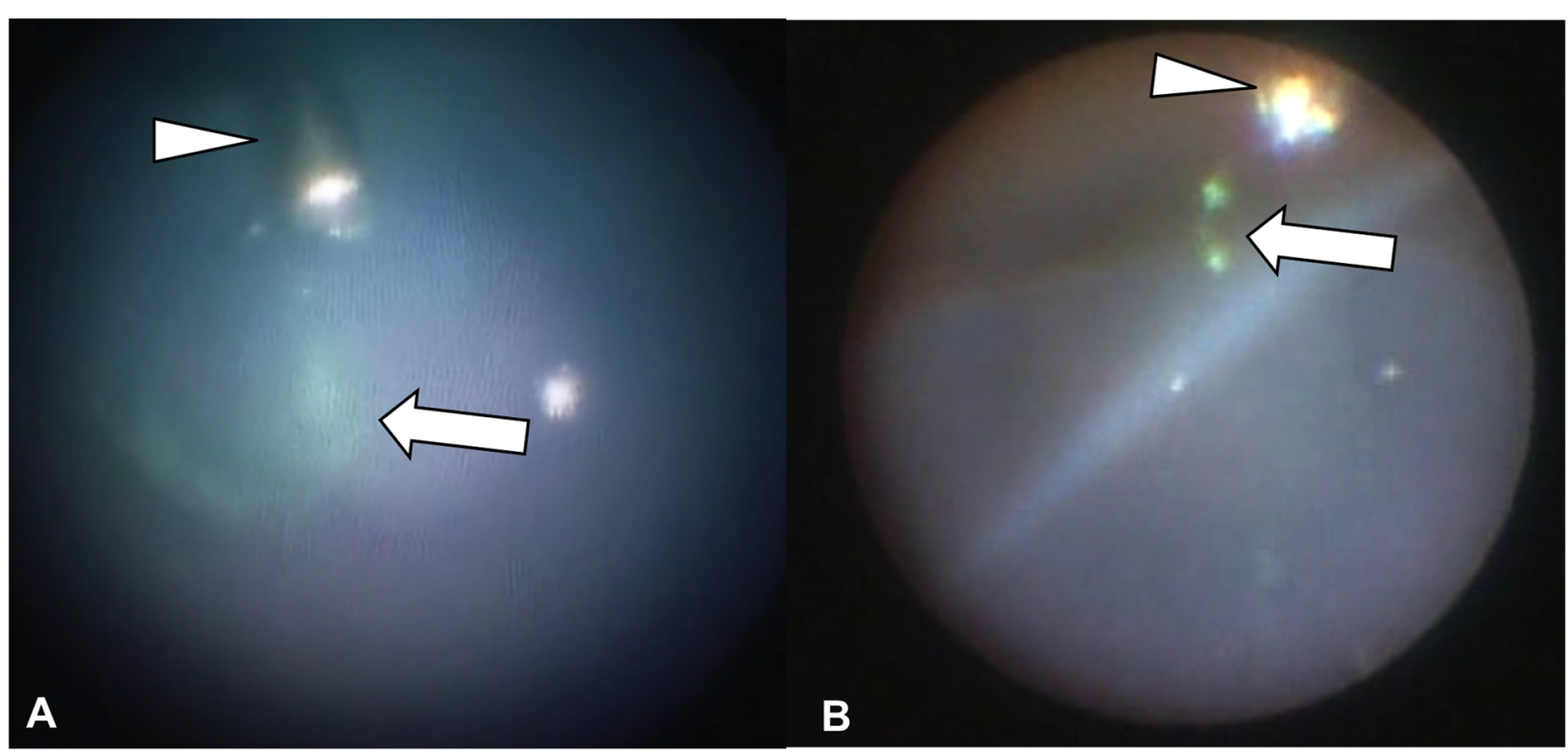

Fig. 3 These procedures were carefully monitored using an intraocular fiber catheter $(\mathbf{a}, \mathbf{b})$. With the injection of saline solution, the microsphere particles were injected through the infusion cannula (arrowhead) and then spread into the vitreous cavity (arrow). We visually detected fluorescent microspheres in 10/10 eyes injected through a 25-G-, and 10/10 with a 27-G, cannula

While not all contamination introduced into the eye is bacterial, previous studies have shown endophthalmitis can develop from just a few bacteria in the vitreous body [8]. Thus, the risk of postoperative endophthalmitis might be increased with MIVS as it inserts a trocar through the conjunctiva. While the irrigation volume could be sufficiently achieved using 20-G, the total irrigation volume will decrease due to the small size of cannula in MIVS. It has been reported that the lower flow volume through the 25-G infusion during surgery as compared with the 20-G cannula, at an approximately 7 -fold lower infusion rate, may diminish the washing effect of the infusion [9]. Furthermore, if the peripheral vitrectomy was not performed effectively to allow wound

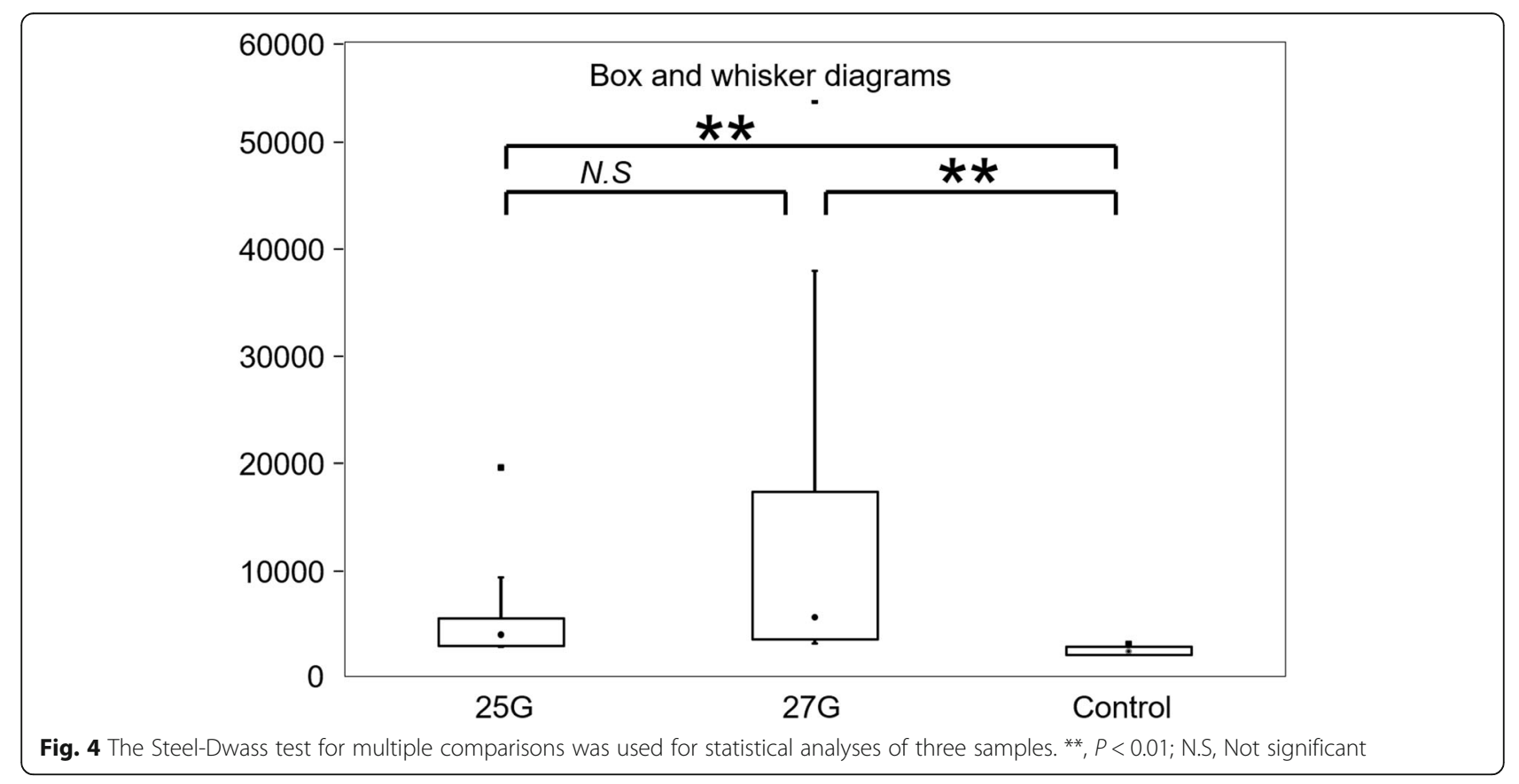


self-closure, it might result in a further reduction in irrigation volume. A report by Tominaga et al. found complete peripheral vitrectomy resulted in a $0 \%$ positive bacterial culture rate in both $20-\mathrm{G}$ and $25-\mathrm{G}$ groups at the end of the operation [4]. In other words, it is possible to remove bacteria adhering to the periphery of the cannula by performing peripheral vitrectomy. Our experiments also show that the contamination from the conjunctiva possibly remains, particularly near the cannula, and that peripheral vitrectomy near the cannula is important in preventing endophthalmitis.

Shimada et al. proposed the concept of intraoperative disinfection that exploited the advantages of shorter disinfection times with $0.25 \%$ PI and fewer side effects on the ocular surfaces [10]. With routine MIVS, they observed a bacterial detection rate of $2 \%$ from the vitreous cavity at the end of vitrectomy, but continuous ocular surface irrigation with $0.25 \%$ PI resulted in a bacterial detection rate of $0 \%$ at the completion of vitrectomy, without any occurrence of endophthalmitis. In MIVS, it is inevitable that contamination on the conjunctiva will penetrate into the eye when the trocar is inserted. However, we are able to prevent the introduction of live bacteria. Therefore, it is of great importance that the ocular surface is disinfected just before insertion of trocar, such as by applying disinfecting agents like $0.25 \%$ PI. It is possible that intraoperative infection can be reduced by such intraoperative infection countermeasures. Additionally, postoperative infection can also be reduced by performing sclerotomies by oblique insertion [11] and using an air tamponade to close the inner valve securely [12], thus lowering the chance of postoperative infection. These measures have lowered the current rate of postoperative endophthalmitis with MIVS [13]. Our study is the first to visually demonstrate that contamination can be brought into vitreous cavity through conjunctiva, even with 27-G MIVS. It is essential that the surgeon be aware of the possibility of introducing contamination on the conjunctiva at all times during surgery, especially when they insert the trocar at the beginning of the MIVS.

The present study has limitations. First, porcine eyes were used as an alternative model for human eyes. The porcine eye has a thicker sclera than the human eye. However, a histological study revealed human and porcine scleras to have a similar histology and collagen bundle organization, indicating that the porcine sclera can serve as a good model for the human sclera [14]. In the human eye, which has a thinner sclera, significantly more bacteria might be introduced, such that our model might underestimate the severity of contamination. Second, the number of experimental cases was small. Yet, we visually detected fluorescent microspheres in 100\% of eyes, and in the experimental quantification study, the fluorescence strength averages differed significantly between the samples and controls. Therefore, we consider the sample size of this study to have been sufficient. Third, in the experimental quantification study, only 0.1 $\mathrm{mL}$ saline solution was injected through infusion canula to obtain samples containing fluoresbrite carboxylate microspheres, and this volume might have been insufficient to wash out all the microspheres adhered to the inner wall of cannula. This might be a reason there was no statistically significant difference between $25-G$ and 27-G.

However, we succeeded in demonstrating that trocar insertion carries a risk of introducing contamination directly into the eyes mechanically, even when a $27-\mathrm{G}$ trocar is used. Thus, disinfection of surgical fields with povidone iodine during surgery seems to be the best way to prevent endophthalmitis after MIVS. The supplementary video will be beneficial for the vitreous surgeon, providing the clear images of how bacteria are introduced into the vitreous cavity during MIVS. Our study has shown it is essential that the surgeon be aware of the possibility of introducing contamination from the conjunctiva at all times during MIVS.

\section{Supplementary Information}

The online version contains supplementary material available at https://doi. org/10.1186/s12886-020-01712-6.

Additional file 1 Supplemental Digital Content 1: Video S1. Enucleated porcine eyes served as a type 1 EVCM. First, an intraocular fiber catheter was inserted at the $12 \mathrm{O}^{\prime} \mathrm{Clock}$ position. Fluoresbrite Carboxylate Microspheres were applied to the conjunctival surface at the insertion site. Then, a 27-gauge trocar cannula was inserted through the conjunctiva and sclera. An infusion cannula was connected to the trocar cannula. With the opening of infusion cannula, the microsphere particles spread into the vitreous cavity.

Additional file 2.

Additional file 3.

\section{Abbreviations}

MIVS: microincision vitrectomy surgery; EVCM: experimental vitreous contamination model

\section{Acknowledgments}

The authors thank Mrs. Akiko Tomioka (Department of Visual Sciences, Division of Ophthalmology, Nihon University School of Medicine) for her expert technical assistance.

\section{Authors' contributions}

YM and HN were the major contributors to the experimental design and drafting of the manuscript. JS analyzed and interpreted collected data. HS contributed to the study concept and design. All authors reviewed and approved the final manuscript.

\section{Funding}

No funding or grant support was used for the writing of this report.

\section{Availability of data and materials}

The datasets used and analyzed during the current study are available from the corresponding author on reasonable request. 


\section{Ethics approval and consent to participate}

This study complied with the tenets of the Declaration of Helsinki. Ethics approval was not required because we used eyes butchered from pigs for food.

\section{Consent for publication}

Not applicable.

\section{Competing interests}

The authors declare that they have no competing interests.

Received: 31 July 2020 Accepted: 29 October 2020

Published online: 10 November 2020

\section{References}

1. Kunimoto DY, Kaiser RS, Wills Eye Retina Service. Incidence of endophthalmitis after 20- and 25-gauge vitrectomy. Ophthalmology. 2007; 114:2133-7. https://doi.org/10.1016/j.ophtha.2007.08.009.

2. Scott IU, Flynn HW, Dev S, Shaikh S, Mittra RA, Arevalo JF, Kychenthal A, Acar N. Eedophthalmitis after 25-gauge and 20-gauge pars plana vitrectomy. Retina. 2008;28:138-42. https://doi.org/10.1097//AE. Ob013e31815e9313.

3. Oshima Y, Wakabayashi T, Sato T, Ohji M, Tano Y. A 27-gauge instrument system for transconjunctival sutureless microincision vitrectomy surgery. Ophthalmology. 2010;117:93-102.e2. https://doi.org/10.1016/j.ophtha.2009. 06.043 .

4. Tominaga A, Oshima Y, Wakabayashi T, Sakaguchi H, Hori Y, Maeda N. Bacterial contamination of the vitreous cavity associated with transconjunctival 25-gauge microincision vitrectomy surgery. Ophthalmology. 2010;117:811-817.e1. https://doi.org/10.1016/j.ophtha.2009. 09.030.

5. Nakashizuka H, Shoji J, Shimada H, Yuzawa M. Experimental visualization and quantification of vitreous contamination following intravitreal injection. Retina. 2016;36:1882-7. https://doi.org/10.1097/IAE.0000000000001028.

6. Inoue Y, Usui M, Ohashi Y, Shiota H, Yamazaki T. Preoperative disinfection of the conjunctival sac with antibiotics and iodine compounds: a prospective randomized multicenter study. Jpn J Ophthalmol. 2008;52:151-61. https:// doi.org/10.1007/s10384-008-0517-y.

7. Speaker MG, Milch FA, Shah MK, Eisner W, Kreiswirth BN. Role of external bacterial flora in the pathogenesis of acute postoperative endophthalmitis. Ophthalmology. 1991;98:639-49. https://doi.org/10.1016/s01616420(91)32239-5.

8. Hatano H, Sasaki T, Tanaka N. Pseudomonas endophthalmitis in rabbits-intravitreal inoculation of two pseudomonal strains. Nihon Ganka Gakkai Zasshi. 1988;92:1758-64.

9. Fujii GY, De Juan E Jr, Humayun MS, Pieramici DJ, Chang TS, Awh C, Ng E, Barnes A, Wu SLSD. A new 25-gauge instrument system for transconjunctival sutureless vitrectomy surgery. Ophthalmology. 2002;109: 1807-12. https://doi.org/10.1016/S0161-6420(02)01179-X.

10. Shimada H, Nakashizuka H, Hattori T, Mori R, Mizutani Y, Yuzawa M. Reduction of vitreous contamination rate after 25-gauge vitrectomy by surface irrigation with $0.25 \%$ povidone-iodine. Retina. 2013;33:143-51. https://doi.org/10.1097/IAE.0b013e318261a6ce.

11. Shimada H, Nakashizuka H, Hattori T, Mori R, Mizutani Y, Yuzawa M. Conjunctival displacement to the corneal side for oblique-parallel insertion in 25-gauge vitrectomy. Eur J Ophthalmol. 2008;18:848-51. https://doi.org/ 10.1177/112067210801800535.

12. Shimada H, Nakashizuka H, Mori R, Mizutani Y, Hattori T. 25-gauge sclera tunnel transconjunctival vitrectomy. Am J Ophthalmol. 2006;142:871-3. https://doi.org/10.1016/j.ajo.2006.05.057.

13. Oshima $Y$, Kadonosono K, Yamaji H, Inoue M, Yoshida M, Kimura H, Ohji M, Shiraga F, Hamasaki T. Japan Microincision Vitrectomy Surgery Sttudy Group. Multicenter survey with a systematic overview of acuteonset endophthalmitis after transconjunctival microincision vitrectomy surgery. Am J Ophthalmol. 2010;150:716-725.e1. https://doi.org/10.1016/ j.ajo.2010.06.002.

14. Nicoli S, Ferrari G, Quarta M, Macaluso C, Govoni P, Dallatana D, Stanti P. Porcine sclera as a model of human sclera for in vitro transport experiments: histology, SEM, and comparative permeability. Mol Vis. 2009;15: $259-66$

\section{Publisher's Note}

Springer Nature remains neutral with regard to jurisdictional claims in published maps and institutional affiliations.

\section{Ready to submit your research? Choose BMC and benefit from:}

- fast, convenient online submission

- thorough peer review by experienced researchers in your field

- rapid publication on acceptance

- support for research data, including large and complex data types

- gold Open Access which fosters wider collaboration and increased citations

- maximum visibility for your research: over $100 \mathrm{M}$ website views per year

At $\mathrm{BMC}$, research is always in progress.

Learn more biomedcentral.com/submissions 